\title{
Organizational Anomie: A Qualitative Research on Educational Institutions
}

\author{
Mehmet Ali YARIM \\ Ministry of Education, Erzurum, TURKEY
}

Sabri ÇELIK

Gazi University, Faculty of Education, Ankara, TURKEY

Received: 22 July 2021 - Accepted: 29 August 2021 • Published Online: 30 August 2021

\begin{abstract}
This study, which aims to examine the perceptions of teachers working in primary and secondary schools regarding organizational anomaly, was designed with a phenomenology study from qualitative research designs. The working group of the research consists of 16 teachers working in state schools in the central districts of Erzurum in 2020-2021. The data obtained with the measurement tool consisting of semi-structured open-ended questions prepared by the researchers were analyzed by content analysis method. According to the findings obtained in the study, the main causes of anomie experienced by teachers are corruption in working life, loss of values, lack of certain rules and norms, distrust of administrators, unwillingness, impossibility, dissatisfaction, inefficiency and loss of belonging. It has been concluded that it has consequences such as lack of discipline, self-interest and negligence, and that the teachers generally have uncertain and anxious thoughts about the personal and social future. In order to reduce anomaly in schools, a value-oriented human resources management based on the spirit of teachers and a transition to a merit and justice-based appointment system in manager appointments are the basic proposals.
\end{abstract}

Keywords: anomie, organizational anomie, worthlessness, normlessness, trust.

\section{Introduction}

There is organic solidarity in traditional societies, organic society has turned into a mechanical society with the effect of the industrial revolution. During this transformation, various social problems have arisen. Developments in the $20^{\text {th }}$ century have also affected the values and norms in the society. With the impact of the industrial revolution, social life has been deeply affected as a result of this change in cultural norms and values. The world has become global and life has changed now. An event happening in one part of the world has affected other locations, no incident originates entirely from local causes and its consequences are not entirely local. In the $21^{\text {st }}$ century, with the effect of globalization and innovation, the norms and values of the western world spread to the traditional eastern societies, and the eastern societies caught unprepared for this spread fell into a void and meaninglessness. In the postmodern world, a great change in mentality has taken place, a secular lifestyle has been adopted. Legal, moral and religious values

(C) Authors. Terms and conditions of Creative Commons Attribution 4.0 International (CC BY 4.0) apply. Correspondence: Mehmet Ali YARIM, Ministry of Education, Erzurum, TURKEY. E-mail: karazeybekli@hotmail.com. 
have changed, the calligrapher lost their importance and evaporated. As a result, individuals have begun to lose their ontological sense of belonging and trust, and have begun to be thrown in the void in an unlimited freedom, worry and anxiety. With the expression of Durkheim, it caused the emergence of anomic behaviors (Yang, 2015).

These changes have pushed people to weakness and loneliness, contrary to a rebirth. Religious institutions, rules, values, worship and rituals, which have an important place in the life of society, have no longer meant anything for the individual and have become unable to fulfill their mission. Norms (abstract rules) in terms of survival, continuity, harmony and function of societies or sociological groups; that is, religious and traditional rules, beliefs and teachings are the basic principles of that society or social group. These socio-cultural norms, which are important in terms of the function of staying healthy, provide social control (Erdoğmuş, 1987, cited in Kasapoğlu, 2019). Along with the anomie experienced in this context, the loss of the power or validity of the rules that are valid in every field and instant of individual and social life among the people on the street, among the drivers in the traffic, among the family members in the family life, in the relations between the school stakeholders in the school, in the entertainment places, the social life is deeply threatened. Individuals stuck under this gripper carried their experiences to the organizations they worked with, and from all this negative situation, organizations and especially schools, where values and virtue should be produced and sustained as a supreme value, took their share and were exposed to organizational anomy (Johnson \& Duberley, 2011).

Derived from the ancient Greek word ánomos “illegal, no rules”, the idea of anomie means the absence of normal ethical or social standards (Zoghbi \& Rodriguez, 2007). This concept arose for the first time in 1893 when the French sociologist Emile Durkheim published his book, Department of Work in Society. In this book, Durkheim states that the rules of individuals' interactions with each other are breaking down and therefore people cannot determine how to treat each other. Durkheim believed that anomia was a situation in which behavioral expectations were uncertain and the system collapsed, and this is now known as normlessness. Durkheim emphasizes that this anomaly leads to deviant behavior and can lead to suicidal consequences.

The norms in a society change depending on developments and changes. As a result of this change, old norms lose their effect and new norms come into being. In this case, some gaps occur in the life of society. In situations such as urbanization, where social change is experienced very rapidly, old norms become unable to meet the requirements and lose their validity is an example of this situation. As a result of the loss of validity of the norms and the decrease in the power of sanction in a society, anomie occurs in the society. According to Durkheim, modern societies based on differences based on division of labor and specialization, where solidarity arising from similarity decreases, and urbanized societies are seen as anomie candidate societies (Özmen, 2019).

Anomie means "balance" and the state of irregularity and normlessness in individual behaviors that arise when the integration is disrupted (Edinsel, 2020; Swingewood, 1998). In general, anomie, which revolves around a psychological state that characterizes a tendency to be self-interested, means rejecting social norms or feeling distanced or isolated from society. In this conceptualization, it includes the feeling that life is meaningless in which feelings of anomie, aimlessness or powerlessness are dominant (Martin, 2000; Kontry, 2005; Baumer, 2007; Bjarnason, 2009).

It is an obvious fact that the deterioration in the social structure, which is an important dimension of the anomie, is closely related to the deterioration of the leadership. When the social structure dimension is q, it puts additional weight on the other. More specifically, leaders become unable to manage problems in society and lose their role as representatives of society (Tyler, 2003; Reicher et al., 2005; Ambrose \& Arnaud, 2005). Later in this process, many people experience a feeling that undermines the sense of belonging in society, and they feel like a stranger who is not 
fairly taken into account. On the other hand, a deterioration in leadership can also cause a deterioration in the social fabric. Similarly, Rothstein and Eek (2009) found that when trust in authorities decreased, general trust in others eroded (Reicher, 2006; Haslam, 2007; Rothstein \& Eek, 2009). Thus, anomie arises when these two dimensions of a functioning society (effective leadership and strong social structure) are eroding. In other words, we can say that anomia occurs both after leadership and after social tissue disruption. Employees feel helpless and hopeless in their ability to work towards their desired goals due to the disruptions in these two dimensions. If a society forces its members to acquire wealth and provides insufficient means to do so, that coercion causes many people to violate norms. In such cases, social behavior becomes unpredictable, and anomic behaviors that range from ritualism, withdrawal to crime, suicide and rebellion occur (Özmen, 2019).

Durkheim sees the anomie as a problem of modern industrial societies. There are six main reasons for the anomie, which weakens the sense of interdependence and solidarity of the individuals in the society and the public morality and deeply shakes the social integration based on the rule of life (Edinsel, 2020):

- Economic fluctuations in society;

- As a result of the development of the social division of labor, the emergence of new occupational groups and the weakening and disappearance of old professions and professional organizations;

- Rapid technical and social developments that make it difficult and slow down the cultural adaptation of individuals;

- The complexity of the rules that ensure adaptation to rapidly changing developments;

- The moral void that emerges with the weakening of the collective consciousness that gives the society a sense of "we" and the inability to form a new collective consciousness, the weakening of the "public authority" in terms of the regulatory power of the society;

- Unfair employment contracts, unfair freedoms.

The concept of anomie has been used to express a situation of normlessness and irregularity that occurs when the rules and order in the social structure do not work or deteriorate. The concept of anomie emphasizes a social situation, that is, a sociological situation, rather than a psychological state of personal and mental origin. It stems from the tension between individual interests and common cultural consciousness (Özmen, 2019). In the lexicon of philosophy, among the causes of the anomie, the depression and depression caused by the weakening of the traditional, especially the moral rules of the society and the individual, and financial difficulties are shown (Ulaş, 2002).

According to Merton (1973), anomie will increase in cases of the aimlessness of the society, the inability of the leaders to meet the demands of the individuals, the loss of the function of the social rules, the society's fear of deficiencies and the future, the thought that there will be no social development, loss of goals, social regression, disintegration among individuals, feelings of hopelessness and insecurity (Kızılçelik, 1992).

Anomie is the state of irregularity and normlessness in individual behaviors that occur when social "balance" and integration are disrupted (Yeniçeri, 2019). Anomie is a concept that deals with both social and individual mental health, as it deeply shakes the understanding that it is possible for individuals in the society to achieve individual goals together and by looking after each other, isolating the individual from the society by isolating them from the society, or derating and making them reckless. Some striking psychological consequences of anomia: loneliness, isolation, difficulty in finding cultural and social direction, alienation, feelings of powerlessness 
and helplessness and suicide. One of the individual consequences of the anomie is suicide, which Durkheim examines as a social phenomenon. Anomic suicides become widespread in the periods of rapid impoverishment or enrichment that occur as a result of rapid social and economic change, when the "public authority", which means the society itself with its regulatory and rule-making organs, is weakened and cannot produce a morality of social solidarity. With the anomaly experienced in societies, rules and norms become dysfunctional, the hierarchy of values turns upside down, and the individual becomes suitable for all kinds of actions (Durkheim, 1966). According to Ekmekçi (2004): "In societies with anomia, disorder and chaos prevail. The common values that make up the society lose their validity. For this reason, crime rates increase rapidly and suicide cases become widespread. In such a society, the individual may feel useless, pointless and in emotional void. In this case, it becomes meaningless for the individual to make an effort for something. Then individuals start to break the rules. From now on, the only regulatory and determining factor becomes the interests of the people."

The consequences of anomy can be expressed as follows: The state of imbalance occurs, common values and meanings are neither understood as before, nor can new values and meanings be substituted for them. Individuals may be resorted to illegal vehicles. In these periods, individuals lose their sense of loyalty to the society and carry their endless desires, which are in their interest, to the extreme. The individual may be dragged into a state of mental disorder and meaninglessness. The individual loses his traditional origins and succumbs to mental depression, the crime rate increases, and suicide events become widespread. In such a society, many individuals are pushed into a psychological position defined by a sense of uselessness, purposelessness, emotional emptiness, and hopelessness. Making efforts for anything is now considered useless; because there is no accepted definition of what to strive for. Individuals start to break the rules. The dimension of social norms that connects people to each other becomes ineffective. Traditional social and personal ties are dissolved, the individual's ties with society weaken or even disappear. The individual's sense of attachment to society is eroded, a general confusion, breakdown and conflict situation arises. Norms become ineffective, a state of breakdown, confusion or conflict arises. Situations of innovation, withdrawal, ritualism, rebellion arise. Since people are less attached to the social order, their basic desires can reach unlimited and mixed dimensions. In an anomic environment, the individual may experience status and role confusion, and fall into mental problems such as affective disorders, personality disorders, identity disorders, behavioral disorders, stress, depression, anxiety and anxiety (Öztürk, 2001; Ekmekçi, 2004; Marshall, 1999; Ulaş, 2002; Cevizci, 2000; Budak, 2000).

There have also been studies at the organizational level on the concept of anomie, which is related to the psychological and sociological processes that constitute the subject of organizational behavior (Switzer, 2013; Skiba, Smith \& Marshall, 2009; Zoghbi \& Rodriguez, 2007; Zoghbi, 2008; Zahra, Priem \& Rasheed, 2005; Bass \& Riggio, 2006). Organizational anomy is a phenomenon in which the individual norms and values of the employees become inefficient, causing the employees to act in an organizationally perverted manner over time, and a deficiency in the perception of the organization's workforce and social suitability (Formiga, Fleury, Fandino \& Souza, 2016). Organizational anomie is the cause of the behaviors that work in the structure of the organization, changing the behavior of deception, changing the conditions for their own benefit, decreasing ethics, mutual commitment and trust in decision-making, guilt and guilt of the employees. In addition, unethical psychological behavior, theft, embezzlement, negative climate and motivation, document fraud, fraud, unrealistic expectation, organizational erosion, destruction of organizational culture, deception, helplessness, obedience, hostility and ruthlessness (Switzer, 2013, Maciejewska, 2016, Zoghbi \& Gonzalez, 2009, Martin, Johnson \& Cullen, 2009; Atteslander, 2007; Lincoln \& Guillot, 2004). It was stated that these determinants should be taken into account in order to diagnose anomic behaviors in the organizational structure and to control the anomia. Because anomy is not regarded as a phenomenon that can be completely eliminated, but as a phenomenon that should be kept under control (Nowodzinski, 
2015). When the worker's anomaly is diagnosed, psychological processes and other special conditions should be approached with sensitivity. Therefore, efforts should be made to understand the norms and their consequences in order to combat the anomaly that develops due to the lack of moral behavior and perspective of the employees in business life and organizational structure, and efforts should be made to create an environment where there is a sense of moral confidence at the organizational level (Martin et al., 2009).

The emotions and behaviors of an individual at the organizational level, that is, the employee, may turn from minor deviating behaviors to large-scale unethical behaviors. Employees with anomic feelings; It is considered possible for them to engage in unethical behaviors such as leaving the workplace early, dealing with private affairs during working hours, using or stealing the products or materials of the organization without permission, misinforming their managers or embezzling money (Maciejewska, 2016). For this reason, the presence and level of anomie within the organization should be defined. Because anomie is an important phenomenon that can cause moral decline or collapse when it occurs and affects all decisions and behaviors in the workplace (Formiga et al., 2016). Based on this information in the literature, it is seen that the organizational level anomie phenomenon can lead to serious organizational problems. Therefore, it is important to conduct new studies on organizational anomia, to examine previous studies and to use their results in combating anomie. From this point of view, examining the existence, level and related factors of organizational anomie in schools, which are the basis of social potential, will make a great contribution to the goals, efficiency, effectiveness and quality of education. The social and organizational life in Turkey is extremely important that the sample of studies on the concept that trifling little work in the field of education to be relevant to this issue increases the importance of this work. In this context, the aim of this study is to examine the opinions of teachers about the perception of anomie at school and its causes.

\section{Method}

\subsection{Research model}

The phenomenology design, one of the qualitative research methods, was used in this study. The phenomenological pattern focuses on phenomena that we perceive but do not have a deep and detailed understanding. Although a research reports stories about the experiences of one or several people, the phenomenological study defines the common meaning of several people's lived experiences with a phenomenon or concepts (Özet, 2014).

\subsection{Working group}

The working group of this research consists of 16 teachers working in primary and secondary schools affiliated to Erzurum Provincial Directorate of National Education in the city center of Erzurum during the 2020-2021 academic year. The maximum diversity sampling approach was used in the selection of the participants. In this context, the participants were diversified in the areas of age, professional seniority, gender, and branch differences. Information about the participants is included in Table 1 . In order to keep the identity of the participants anonymous, the pseudonym was used instead of naming the participants directly.

Table 1. Demographic Information

\begin{tabular}{llcc}
\hline Participants & Age & Gender & Branch \\
\hline Sevda & 38 & Female & school teacher \\
Serhat & 54 & Male & school teacher \\
Latif & 40 & Male & Religion \\
Mehmet & 34 & Male & school teacher
\end{tabular}




\begin{tabular}{llcc} 
Murat & 26 & Male & spor \\
Ferda & 52 & Female & Turkish \\
\hline Işıl & 36 & Female & Inglish \\
Erkan & 30 & Male & Math. \\
Arzu & 48 & Female & Guidance \\
Dilara & 46 & Female & Technology Design \\
Ayşe & 29 & Female & Science \\
Ömer & 51 & Male & Social studies \\
Ali & 41 & Male & Turkish \\
Pinar & 36 & Female & school teacher \\
Meryem & 50 & Female & Social studies \\
Hülya & 29 & Female & English \\
\hline
\end{tabular}

As seen in Table 1, 9 of the participants are women and 7 of them are men. Looking at the ages of the participants, it is seen that they are between 26 and 54.4 of the participants are classroom teachers, 1 is science, 1 is physical education, 1 is religious culture and ethics, 2 is Turkish, 2 is English, 1 is math, 1 is counseling, 1 is a technology design teacher and 2 is a social studies teacher.

\subsection{Data collection tools}

In the study, semi-structured interview forms consisting of open-ended questions were created to collect data. The research questions were prepared based on the expressions in the scales related to organizational anomaly after theoretical examination in the literature. Durkheim, Merton, and Srole's anomie theories have focused on elements such as the weakening of values, norms and rules, desperation, social and individual despair, business environment, management style, employee behavior, managerial and social insecurity, unethical behaviors of managers (Heydari et al., 2011; Maciejewska, 2016; Teymoori, 2016; Cullen et al., 2004; Caruana et al., 2001; Switzer, 2013). These elements were taken into consideration in the research questions prepared in this context and a draft interview form was prepared. The prepared draft form was consulted with three faculty members who are experts in the department of educational management, a preliminary interview was made with two teachers before the form was finalized, and the application process was initiated after the necessary corrections were made. The interviews were carried out by the researcher in one-on-one interviews with the participant in January and February of the 2020-2021 academic year. The interviews lasted between 15 and 30 minutes. The questions in the interview form are as follows:

1. What do you think about the impact and validity of today's values, rules and norms in social and personal life?

2. What are your views on the profile and practices of current administrators and school principals?

3. What do you think about today's business life, your own business life and the relationships here?

4. If you could, would you consider retiring or changing jobs, why?

\subsection{Analysis of data}

Content analysis technique was used to analyze the data obtained in the study. Content analysis consists of four stages. In the first stage, the data is encoded, then themes are created by classifying the encoded data, codes and themes are organized, and at the last stage, the findings are defined and interpreted (Yıldırım \& Şimşek, 2013). Content analysis technique was used to 
analyze the data obtained in the research. Content analysis consists of four stages. In the first stage, the data is coded, then the coded data is classified and themes are created, codes and themes are organized, and in the last stage, the findings are defined and interpreted (Yıldırım \& Şimşek, 2013). Accordingly, first of all, the data were coded separately. Then, categories were created in these codes based on the literature. In the last stage, the data were calculated as frequency and percentage values.

2.5 Information on the credibility, transferability, reliability and confirmability of the research

In order to increase the credibility of the research, the opinions of the participants about the findings, comments and results were taken. In order to increase the transferability of the study, the research sample was defined in detail, and each stage of the study was explained in a clear and understandable way. Before starting the interview, a conversation was held with each participant for the purpose of building trust and getting to know each other (Lincoln \& Guba, 1986).

The stability in the answers of more than one coder regarding the data sets is perceived as an indicator of reliability in qualitative studies (Creswell, 2016). The reliability of the study was calculated by Miles and Huberman's (1994) Reliability Formula = Consensus / Consensus + Disagreement. The codes and themes were sent to another expert in the field of educational sciences, and this expert was asked to reclassify the codes under the heading of the determined themes. In the classification made by the experts and researchers, the agreement rate was found to be $76 \%$. A consensus (reliability) of more than $70 \%$ between field expert and researcher evaluations is a valid rate for the reliability of the research (Miles \& Huberman; 1994). Codes classified under different themes were re-examined by field experts and researchers and placed on agreed themes. At the last stage of the analysis, the findings were interpreted (Ylldirım \& Şimşek, 2013). Consent of the participants was obtained for the interviews, and all interviews were conducted on a voluntary basis. Participants were also informed that the data would only be used for scientific purposes and that their personal information would be kept confidential.

\section{Results}

In this study, which aims to determine teachers' perceptions of organizational anomie, the data obtained through interviews were discussed according to themes and sub-themes. According to the data obtained; general anomie: current understanding of value and future perception, managerial trust: current managerial value understanding and valid managerial values, organizational anomie: relational value understanding, organizational anomie and organizational behavior relation, current teacher behavior's themes were formed. Of the 16 teachers who participated in the study, 12 (Sevda, Murat, Ferda, Işıl, Erkan, Arzu, Dilara, Ayşe, Ömer, Ali, Hülya, Meryem) had negative views on organizational anomia, and 4 (Pınar, Serhat, Latif, Mehmet) they usually have positive perceptions. Three candidates who have a positive perception of organizational anomia are male. According to these findings, it can be said that teachers mostly experience organizational anomies and female teachers experience more organizational anomies than men. Three of the four participants who have positive thoughts about organizational anomy are classroom teachers and one is religious culture and ethics teachers. This finding shows that branch teachers experience more organizational anomie than classroom teachers. The themes created from the data obtained and some of the relevant participant views are presented below. 


\subsection{General anomie: Worth my day}

"What do you think about the effect and validity of current values, rules and norms?" and "What are the reasons for this situation?" the questions have been posed. Most of the teachers stated that these values have lost their influence today and that people now believe in these values, but in fact they do not care about these values and rules. The codes formed from teachers' current understanding of value; divergence (2), stricture, normlessness (3), isolation, disregard (3), degeneration (4), worthlessness (5), backwardness, ineffectiveness, irregularity (6), weakening. The codes regarding the cause of this situation are: technology (7), social and virtual world (6), media (6), changing social order (8), family structure (5), wannabe (5), alienation (3), individual life (3). Two of the participants stated that these rules and values are still valid. The positive codes created regarding the opinions of the participants are order (2), commitment (2) and obligation. Some of the participant views are given below.

"In the developing world, unfortunately, people have moved away from social values and norms, got stuck in their inner worlds with technology and individualization, became lonely and became anti-social individuals thinking about their own interests. This caused corruption...” (Ömer)

"Values do not have as much effect in social life as before. Self-interest and materialism have replaced this value. The reason for this situation is the changing society and family structure, affection and media..." (Ayşe)

"Although the values are decreasing in the life of society, they still have an effect. Rules are very effective ..." (Serhat)

\subsection{General anomie: Perception of the future}

"What do you think about personal and social future in the context of current rules, values and norms?" the question has been posed. Twelve of the participants were hopeless about the social and personal future and made negative statements. Codes created based on participant views; despair (8), anxiety (6), loneliness (4), taking precautions (3), lack of culture, intolerance, collapse (3), regression. Three of the participants stated that they have positive thoughts about the future (codes: hope (2), wealth, improvement). Some of the participant expressions are presented below.

"With the weakening of values and rules in the future, individuals will become more and more selfish and alienated. A world without these values and rules would consist of chaos, I think these values will weaken even more...” (Işll)

I see the future of society in loneliness and despair just like my own. I think there will be a series of people living for him ... (Sevda)

With globalization, people stuck in four walls will degenerate, become individualized and move away from values. We have to take measures for these now... (Erkan)

Despite everything, I am hopeful for the future. With education, we will become a society that abides by the rules ... (Latif)

\subsection{Managerial trust: Valuable life and practice}

To the participants, "What do you think about the current administrators and school principals (in the context of living and applying values such as trust and justice)?" the question has been posed. Except for two of the participants, others think that administrators and school principals have negative qualities in terms of living and applying concepts such as trust and justice. Negative codes created in this sub-theme; positive codes being worthless (5), mediocrity (2), 
incompetence (7), norms (4), injustice (8), hypocrisy (6) and insecurity (6), trust (2), justice (3), respect (2). According to these data, it shows that there are negative perceptions in the context of trust between teachers and school principals. Although only 4 teachers trust school principals and administrators, 12 teachers find school principals insecure and unfair. Some of the participants' views on this sub-theme are as follows:

"I cannot trust the principal in general. I think he remained silent in order to maintain his position in every matter and could not put what he said into practice. I cannot see the knowledge and value that should be in the manager..." (Arzu)

"School principals cannot give confidence to the people as they do not trust themselves first. Since there is anxiety and fear of being complained in their actions, they approach people and events with suspicion and take responsibility and do not take risks, and teachers can sell them immediately. For this, they lack justice and trust...”(Ali)

"We work in one of the ministries with the highest number of personnel. There are many candidates for management in such a crowded group. Among them, the number of insecure and unfair managers is not small and I do not believe that they live up to values...” (Dilara)

"I see what they say is the same as what they do. I trust my school principal..." (Pınar)

\subsection{Managerial trust: Valid managerial values}

"What do you think about the values and facts that apply to today's administrators and school principals?" the question has been posed. Ten of the participants expressed negative opinions on this issue and stated that the behavior of school principals and administrators today consists of actions taken to protect their positions rather than values. The codes created in this sub-theme: negative codes such as cringe (4), nepotism (7), all-ways permissiveness (4), patronage, unionism (5), subversion (3), not something to me, favoritism (5) and diligence (3), positive codes such as honesty (3) and innovativeness. Some of the expressions of the participants are given below.

“Today's principals cringe to become principals and continue, they do everything they say, take everything from bottom to bottom against parents and superiors, and unions do whatever they say..."(Arzu)

"Unfortunately, they say that they would do anything to get this position because they found and appointed an incompetent man and they care so much about this seat. They treat their subordinates as if they were a boss and remain silent towards their superiors..." (Hülya)

"They have the values to work, to be innovative and to drive the school forward, and they work honestly for that..." (Serhat)

\subsection{Organizational anomie: Values in relationships}

"Mutual trust, meaning of work, ethics, justice, respect, tolerance, etc. When you evaluate it in the context of values, how do you evaluate today's working environments and their relations?" the question has been posed. Although 11 of the participants expressed negative opinions on this question, 5 of them expressed positive opinions. Negative codes created in this sub-theme; positive codes when grouping (2), interests' relations (6), unethical, intolerance (4), insecurity (8), harming (3), resistance, insincerity (4); trust (3), tolerance (3), respect (5) and togetherness (4). The statements of some of the participants are as follows: 
"Relationships are damaged because there is no value left in relationships. Tolerance and tolerance have decreased, people have no trust in each other. Since there are no moral and ethical values, the relationships are superficial ..."(Meryem)

"This situation depends entirely on where the person works. I find my environment very good. Relationships at my school have a family atmosphere of fair, diligent and reliable people." (Serhat)

"Although the relationships seem tight in the environment I work in, there is interest and insincerity. In the changing world, values have decreased and relationships have been damaged ..” (Dilara)

\subsection{Organizational anomy: Values in organizational behavior}

To the participants, "What kind of behaviors do the existence or absence of the current value rules and norms cause in organizational terms?" The question has been posed. Although 13 of the participants expressed negative opinions, three of them expressed relatively positive opinions. Negative codes created in this sub theme in line with the data obtained: organizational failure (7), lack of motivation (9), organizational distancing (7), negative school climate (6), morale (10), indiscipline (5), inefficiency (4), organizational withdrawal (9), dissatisfaction (8); and positive codes depletion (6): satisfaction (3), positive culture (2), organizational trust (3) and commitment (2). Some of the participants' views are as follows:

"Because all these values are weakened, teachers do not feel that they belong to their school and they experience professional dissatisfaction. Low motivation at school leads to an unsuccessful and poor school..." (Murat)

"Because the values decrease in the teachers in the school, there is insecurity, the teachers are unhappy, they do not obey the work discipline, they cannot commit themselves to their work ..." (Ferda)

"The more these values in the school, the more confidence increases, the relationships improve, the teachers find what they are looking for...” (Mehmet)

\subsection{Organizational anomy: Teacher behaviors today}

"How do you evaluate teacher behaviors in the context of valid values, norms and rules in today's business life?" to the participants, the question was posed. Although 12 of the participants tried to explain today's teacher behaviors with negative expressions, 4 of them made positive expressions in general understanding. The positive ones among the codes in this subtheme created according to the teachers' opinions: I save the day (5), do whatever they say (6), despair (5), frustration (4), withdrawal (8), loss of excitement (8), timidity (2), avoidance of responsibility (3), selfish; but positive codes: self-sacrifice (3), diligence (3), sacrifice (2), love of profession (2). Some of the teachers' views on this sub-theme are below:

"Now that the teachers do not see justice in their jobs, they go in and out of their classrooms rather than work too hard and they do not give their opinion on any job, they only think about the salary they will receive ..."(Ali)

"When we ask, there are things that nobody wants to do but everyone does involuntarily in order to be a cogwheel in the functioning. This ends teachers' commitment, happiness and excitement...” (Işll)

"Despite all the difficult conditions today, teachers are doing their best. They are devoted to students, despite all kinds of humiliation and deterrence. In this age, a teacher who does not do his job fondly cannot be happy..." (Latif) 


\subsection{Job satisfaction}

Finally, to the participants, "When you think about the developments in society and business life, would you consider retiring or changing jobs if you could, why?" the question has been posed.

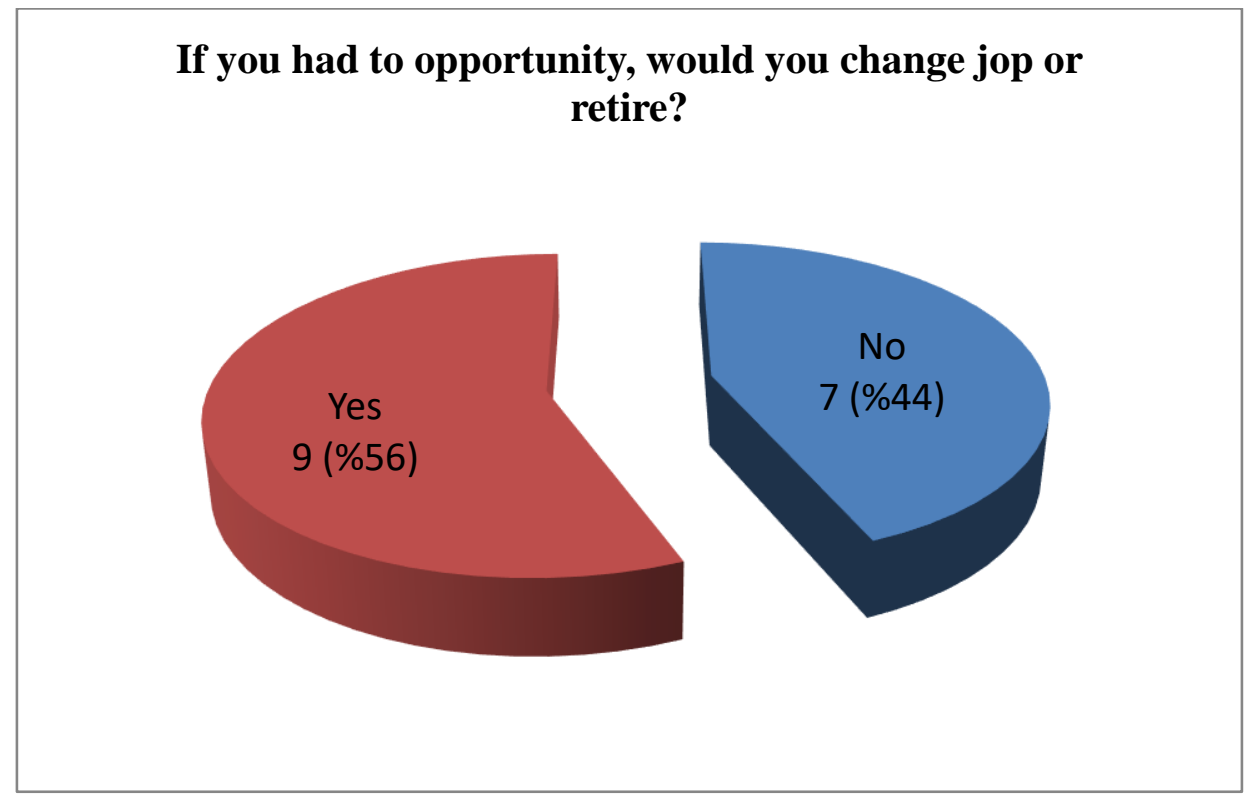

Figure 1. Job Satisfaction Chart

As can be seen in Figure 1, 9 of the teachers stated that they could change jobs or retire if they had the opportunity, considering the current conditions. 6 of the participants stated that they are satisfied with their work. Negative codes occurring under this theme: injustice (7), incompetent managers (5), insecurity (7), selfishness (3), materialism, anxiety (2) and loss of dignity of the profession; positive codes are love of profession (5), respectable profession (5), devotion (3). Some of the teachers' views on this theme are below:

"I love my job very much, even if I have a chance, I will not quit it..." (Mehmet)

"If I had such an opportunity, I would consider changing jobs and moving to a highreturn job. Because I am tired of the incompetence of the managers and the fact that the person who finds his man has a seat ...” (Işıl)

"I worked hard to earn this prestigious profession, whatever the conditions are, it is above all for a student to learn something from me ..." (Meryem)

\section{Conclusion and discussion}

According to the statements of the participants, most of the teachers think that the values and norms have lost their influence in today's social and personal life and the rules are ignored. Today, although there are those who think that the effects of values and rules continue, they remain a minority among the participants. According to these findings, the general anomie levels of most of the teachers are high and according to these teachers, the effect of values, norms and rules in the society is weak. Teachers see phenomena such as media, technology, changing social life, wantingness and individualization as the reason for this situation. Most of the participating teachers are hopeless about the future due to the current state of today's world, they are worried about the future and they have negative expectations for the future. Bayhan (1995), in his study on university students, concluded that $98 \%$ of the participants experienced moderate 
anomie. In this study, Bayhan (1995) concluded that negative family characteristics, living environment, socio-economic structure, ideology, social structure and friendship are also effective in the anomy experienced by young people. When we associate the opinion of the participants of the present study with the idea that Bayhan (1995) was a student at the time of the research, it can be interpreted that the medium-level anomie potential in almost all of the individuals was triggered by the practices in professional life and turned into a behavior. Fandine et al. (2015) focused on the relationship between the perception of organizational support and lack of selfidentity and anomia. According to Messner and Rosenfeld (2006), the four institutional forces associated with the institutional anomie theory are; economy, education, politics and family. Heydari, Davoudi and Teymoori (2011) anomie; They examined it in the context of meaninglessness, weakness, insecurity and excessive indulgence in money, and they saw materialism as the most important reason for the emergence of anomy.

Participants stated that although they are primarily responsible for living the values, norms and rules in society, today's administrators feel a deep distrust, especially of school principals. According to the teachers, school principals try to protect their positions by applying only what the superiors say and the rules, and they work to stay in their seats rather than to raise the educational level or to use human resources effectively. According to the expressions of the participants, today's administrators and school principals are inadequate in living and applying values and norms. Among the participants, although there are some who have positive thoughts about the administrators in the context of facts such as trust, value and justice, their number is small. Generally, when the participants talk about administrative trust, concepts such as lack of merit, worthlessness, injustice, protecting their seat, taking their seat, unionism and lack of vision come to mind. Participants generally do not trust managers, think that they do not attach importance to values and norms and have negative thoughts. Arslan and Yavuz (2019) also concluded in their study that anomia in organizations is closely related to justice and trust. Cullen et al. (2004) states that managers' behaviors in terms of the concept of justice and ethics are in harmony with the organizational anomie. It has been found out that organizational culture, structure, management style, immoral behavior and unethical behavior in an organization increase employee anomaly (Jahanshahi \& Dehghani, 2019; Sypniewska, 2017). Bass and Riggio (2006) in their study associating anomie and transformational leadership; they emphasized that the practices of transformational leaders are effective in gaining important goals, meanings and values that employees need and are related to anomia. Teymoori (2016) also discussed anomaly at two levels, namely the erosion of the social structure and the deterioration of leadership, and found that the dissolution in the social structure and the disturbances in leadership increase the sense of helplessness and hopelessness and cause anomia.

Participants generally develop trust, ethics, justice, respect, tolerance, etc. in relationships in their work environment. They stated that values have lost their importance, instead of them, self-interest, individuality, intolerance and intolerance prevail. According to teachers, although individuals say that they believe in so-called values, when it comes to their own interests, they can give up these values very quickly. This degeneration and deregulation experienced in values and norms in organizational life causes organizational behaviors such as exhaustion, lack of motivation, organizational withdrawal, inefficiency, insatiability, unhappiness, indiscipline, withdrawal, negative school climate and culture. Although there are participants who say that teachers exhibit positive behaviors in an individual sense, according to the vast majority of participating teachers, the behavior of today's teachers is shaped by the effect of frustration, despair and negligence with the thought of doing whatever they say. Cohen (1993) concluded that there are relationships between organizational anomaly and organizational culture, ethical climate in the organization, leadership, and organizational socialization. In many studies in the foreign literature on the subject, they emphasized that anomia has effects on employee hopelessness, feelings of helplessness and incompatible perceptions not related to the expectations of the 
enterprise, burnout, withdrawal, lack of motivation, and low performance (Penc, 2011; Tsahuridu, 2011; Zoghbi \& Gonzalez, 2009; Carter \& Carter, 2007; Zoghbi \& Rodriguez, 2007).

Although most of the participants think negatively in terms of general and organizational anomie and trust in the manager, it is seen that the statements are not that negative when it comes to professional satisfaction. Despite this, more than half of the participants are not satisfied with their jobs due to the worthlessness, irregularities and irregularities in working life and they want to change jobs or retire if they have the opportunity. Similarly, Choi et al. (2018) found in their study that anomia causes workplace deviation and job change in employees.

According to the results of this study conducted on primary and secondary school teachers, the general anomie and organizational anomie perceptions of the teachers are high. The organizational anomie perceptions of the participants who are classroom teachers are very low compared to the branch teachers. Teachers are deeply distrustful of today's administrators and school principals due to their lack of values and norms. In the context of this anomie and insecurity experienced, the negativities in the phenomena such as organizational behavior, school success, efficiency, satisfaction and job arrest deeply threaten the school and its employees.

follows:

According to the results obtained from the research, the recommendations are as

- One of the most important components of the organizational anomie experienced by teachers is the distrust towards the administrator. In this context, it is necessary to create an appointment model that gives importance to merit and justice by eliminating variables such as trade unions, politics and favoritism in the appointment of administrators to schools. For this, an appointment model should be made in cooperation with universities in each province. For this purpose, the commissions, which will be formed under the presidency of lecturers with at least associate professors in the departments of education management in universities, who are experts in this field, and that will be made up of administrators and stakeholders who have come to the fore with their local experience, expertise and value should be functionalized.

- Enriching current principals in the context of values and social norms can help reduce organizational anomaly in schools by increasing trust in school principals.

- Teachers think that values in relationships in their schools become insignificant and self-interest and irresponsibility are very high. For this, the ministry's transition to a human resources management system and personnel evaluation system, which takes into account the relationships in schools, where the teacher willingly enters into work not with threats based on investigation and punishment methods, they feel valued, justice and ethical rules prevail, may help reduce organizational anomaly in schools.

- Written and spoken rules, whose importance is emphasized by fancy sentences as discourse everywhere; The most important factor in the survival and implementation of values such as justice, ethics, equality, tolerance and social norms is the living and implementation of the managers and decision makers from the highest to the lowest. In the context of managerial practices, employees who see that these remain only in writing and in words, quickly move towards the depths of the organizational anomie. In this context, starting from the top level, regardless of the conditions, not compromising these rules and values and pushing those who try to damage them out of the system will be one of the most important steps to prevent anomia in schools.

- Increasing the organizational anomie studies, which are insufficient in our country's sample, and examining the reasons and consequences of this concept at all types and levels in education, in solving the current problems and dilemmas in our education, overcoming inertia and congestion, and most importantly, encouraging teachers, who are the locomotives of education, to be involved and show their potential. It will make very important contributions in terms of. 


\section{Acknowledgements}

This research did not receive any specific grant from funding agencies in the public commercial, or not-for-profit sectors.

The authors declare no competing interests.

\section{References}

Ambrose, M. L., \& Arnaud, A. (2005). Are procedural justice and distributive justice conceptually distinct? In J. Greenberg \& J. A. Colquitt (Eds.), Handbook of Organizational Justice (pp. 59-84). Mahwah, NJ: Lawrence Erlbaum Associates Publishers.

Arslan Ö. E., \& Yavuz, E., (2019). Örgütsel adalet, örgütsel anomi ve örgütsel güven arasındaki ilişki: otel işletmelerinde bir araştırma [The relationship between organizational justice, organizational anomie and organizational trust: A research in hotel businesses]. Turkish Studies International Periodical for the Languages, Literature and History of Turkish or Turkic, 14(2), 113-134.

Bass, B. M., \& Riggio, R. E. (2006). Transformational leadership (2nd Edition). Mahwah, NJ: Lawrence Erlbaum.

Baumer, E. P. (2007). Untangling research puzzles in Merton's multilevel anomie theory. Theoretical Criminology, 11(1), 63-93.

Bayhan, V. (1995). Üniversite gençliğinde anomi ve yabancılaşma (İnönü Üniversitesi örneği) [Anomie and alienation in university youth (Inonu University example)] (Unpublished PhD Thesis). İnönü Üniversitesi, Sosyal Bilimler Enstitüsü, Malatya.

Bjarnason, T. (2009). Anomie among European adolescents: Conceptual and empirical clarification of a multilevel sociological concept. Sociological Forum, 24(1), 135-161.

Carter, E. M., \& Carter, M. V. (2007). A social psychological analysis of anomie among national football league players. International Review for the Sociology of Sport, 42(3), 243-270.

Caruana, A., Ramaseshan, B., \& Ewing, M. T. (2001a). Anomia and fraudulent behavior by retail customers: A study among employees. Journal of Retailing and Consumer Services, 8(1) 181-187.

Choi, Y. H., Myung, J. K., \& Kim, J. D. (2018). The effect of employees' perceptions of CSR activities on employee deviance: The mediating role of anomie. Sustainability, 1O(3), 1-20.

Cohen, D. V. (1993). Creating and maintaining ethical work climates: Anomie in the workplace and implication for managing change. Business Ethics Quarterly, 3(4), 343-358.

Creswell, J. W. (2013). Nitel araştirma yöntemleri [Qualitative research methods]. M. Bütün \& S. B. Demir, Trans. (Eds.). İstanbul: Siyasal Kitapevi.

Cullen, J. B., Parboteeah, K. P., \& Hoegel, M. (2004). Cross-national differences in managers' willingness to justify ethically suspect behaviors: A test of institutional anomie theory. Academy of Management Journal, 47(3), 411-421.

Durkheim, É. (1966). Suicide, a study in sociology. New York, NY: Free.

Edinsel, K. (2020, 12 January). Anomi. https://dusunbil.com/2020/01/anomi-nerede-ne-zaman-ve-nasil/.

Fandino A., Aguiar, S. M., \& Bentes, S. R. (2015). Organizational anomie, professional self-concept and organizational support perception: theoretical model evidences for management. International Journal of Business and Social Science, 6(11), 1-10. 
Fritsche, I., Jonas, E., \& Kessler, T. (2011). Collective reactions to threat: Implications for intergroup conflict and for solving societal crises. Social Issues and Policy Review, 5(1), 101-112.

Haslam, S.A. \& Reicher, S. (2007). Identity entrepreneurship and the consequences of identity failure: the dynamics of leadership in the BBC prison study. Social Psychology Quarterly, 7o(2), 125-47.

Heydari, A., Davoudi, I., \& Teymoori, A. (2011). Revising the assessment of feeling of anomie: Presenting a multidimensional scale. Procedia - Social and Behavioral Sciences, 30, 1086-1090.

Jahanshahi, A. A., \& Dehghani, A. (2019). Anomie at public organizations: How can the quality of work life help? Journal of Public Affairs, 2O(4), 1-9.

Johnson, P., \& Duberley, J. (2011). Anomie and culture management: Reappraising Durkheim. Organization, 18(4), 563-584.

Kasapoğlu, O. (2019). Anomi sürecinde toplumsal kaos [Social chaos in the process of anomie] (Master's Thesis). Sosyal Bilimler Enstitüsü. Cumhuritey Üniversitesi, Sivas.

Konty, M. (2005). Microanomie: The cognitive foundations of the relationship between anomie and deviance. Criminology, 3(1), 107-32.

Lincoln, Y. S., \& Guba, E. G. (1986). But is it rigorous? Trustworthiness and authenticity in naturalistic evaluation. New Directions for Program Evaluation, 30, 73-84.

Martin, R. (2000). Anomie, spirituality, and crime. Journal of Contemporary Criminal Justice, 16(1), 7598.

Messner, S. F., \& Rosenfeld, R. (2006). The present and future of institutional-anomie theory in taking stock: The status of criminological theory (Cullen, F. T., Wright, J P., \& Blevins, K. R., Eds.). New Brunswick: Tran Saction.

Miles, M. B., \& Huberman, A. M. (1994). Qualitative data analysis: An expanded Sourcebook (2 ${ }^{\text {nd }}$ ed). Thousand Oaks, CA: Sage

Özmen, Ü. (2019, 10 December). Anomi hastahğı. https://www.birgun.net/2019/12/haber/ahlaksizlikhastaligi-anomi-194581.

Penc, J. (2011). Organizational behavior in the enterprise. Steering creative attitudes and aspirations. Warsaw: Wolters Kluwer Polska. (in Polish)

Reicher, S., \& Haslam, S. A. (2006). Rethinking the psychology of tyranny: The BBC prison study. The British Journal of Social Psychology, 45(1), 40-52.

Reicher, S., Haslam, S. A., \& Hopkins, N. (2005). Social identity and the dynamics of leadership: Leaders and followers as collaborative agents in the transformation of social reality. The Leadership Quarterly, 16(4), 547-568.

Rothstein, B., \& Eek, D. (2009). Political corruption and social trust an experimental approach. Rationality And Society, 21(1), 81-112.

Rothstein, B. (2000). Trust, social dilemmas and collective memories. Journal of Theoretical Politics, 12(4), 477-501.

Switzer, T. G. (2013). Measuring normlessness in the workplace: A study of organizational anomie in the academic setting [A Ph.D]. Dissertation in Leadership and Change Program, Antioch University.

Sypniewska, B. A. (2017). Work anomie in an organisation. International Journal of Contemporary Management, 16(2), 235-265.

Şimşek, M., Şerif, Akgemci, T., \& Fettahlığlu, T. (2006). Örgütlerde yabancılaşmanın yönetimi. Örgütlerde yabancılaşmanın yönetimi örgütlerde araştırması [Management of alienation in organizations. Management of alienation in organizations research in organizations]. Selçuk Üniversitesi Sosyal Bilimler Enstitüsü Dergisi, o(15), 569-587. 
Teymoori, A., Jetten, J., Bastian, B., Ariyanto, A., Autin, F., Ayub, N., et al. (2016). Anomi ölçümünü tekrar gözden geçirme [Reviewing the anomie measurement]. PLoS ONE, 11(7), e0158370. https://doi.org/10.1371/journal.pone.0158370

Teymoori, A. (2016). The psychology of anomie [Doctoral Dissertation]. The University of Queensland School of Psychology, Australia.

Tsahuridu, E. E. (2011). An exploration of factors affecting work anomia. Journal of Business Ethics, 99(2), 297-305.

Yang, a. (2015). Quantifying anomia: Development of a scale. Master Thesis. California State University, Fresno.

Yeniçeri, Ö. (2019, 12 December). Anomi ve epistemik çöküş. Yeniçă̆.

https://www.yenicaggazetesi.com.tr/2019/12/anomi-ve-epistemik-cokus-51039yy.htm.

Yıldırım, A., \& Şimşek, H. (2006). Sosyal bilimlerde nitel araştırma yöntemleri [Qualitative research methods in the social sciences]. Ankara: Seçkin Yayıncılık.

Zoghbi, P., \& Gonzales, S. M. (2009). The role of anomia on the relationship between organisational justice perceptions and organisational citizenship online behaviours. Journal of Information, Communication \& Ethics in Society, 7(1), 72-85.

Zoghbi, P., \& Rodriguez, T. E. (2007). Organizational anomie as moderator of the relationship between an unfavorable attitudinal environment and citizenship behavior (OCB): An empirical study among university administration and services personnel. Personnel Review, 36(6), 843-866. 